\title{
Immunomodulatory and anti-inflammatory effects of hydro-ethanolic extract of Ocimum basilicum leaves and its effect on lung pathological changes in an ovalbumin-induced rat model of asthma
}

\author{
Naima Eftekhar ${ }^{1}$, Ali Moghimi ${ }^{1}$, Nema Mohammadian Roshan², Saeideh Saadat ${ }^{3}$ and \\ Mohammad Hossein Boskabady ${ }^{4,5^{*}}$
}

\begin{abstract}
Background: Ocimum species (Lamiaceae) has been traditionally used for treatment of upper respiratory tract infections, bronchitis, coughs, sore throat, and wound healing. The Immunomodulatory and anti-inflammatory effects of hydro-ethanolic extract of Ocimum basilicum (O. basilicum) leaves was examined in ovalbumin sensitized animals.

Methods: Wistar rats were divided to six groups; non-sensitized, sensitized to ovalbumin, sensitized and treated with dexamethasone $(1.25 \mu \mathrm{g} / \mathrm{mL})$, and 0 . basilicum extract $(0.75,1.50$ and $3.00 \mathrm{mg} / \mathrm{mL})$ in drinking water for 21 days. The levels of interleukin 4 (IL-4), interferon gamma (IFN- $\gamma)$, IFN- $/ / L-4$ ratio, immunoglobulin $E(\operatorname{IgE})$, phospholipase $A_{2}\left(P L A_{2}\right)$ and total protein (TP) in BALF, and lung pathological changes were examined.

Results: A significant increase in IL-4, IgE, PLA $A_{2}$ and TP levels, all lung pathological indices as well as significant decrease in IFN- $\gamma / \mathrm{IL}-4$ ratio was seen in the asthmatic compared to the control rats $(P<0.05$ to $P<0.001)$. Treatment with 0 . basilicum extract resulted in decreased IL-4, IgE, PLA $A_{2}$ and TP levels, but increased IFN- $\gamma / \mathrm{IL}-4$ ratio compared to untreated sensitized rats $(P<0.01$ to $P<0.001)$. The plant significantly improved the pathological changes of sensitized rats $(P<0.05$ to $P<0.01)$. The improvement effects of higher concentrations of the 0 . basilicum extract were significantly more than those of dexamethasone $(P<0.05$ to $P<0.001)$.
\end{abstract}

Conclusion: The improvement effects of $O$. basilicum on pathological changes, immunological and inflammatory markers in sensitized rats comparable or even more potent than dexamethasone suggests the therapeutic potential of the plant in asthma.

Keywords: Ocimum basilicum, immunological mediators, Inflammatory mediators, Asthma

\section{Background}

Airway inflammation and tissue remodeling of the airway structure are two main pathophysiologic characteristic of asthma which mediated by numerous cells and their mediators $[1,2]$. In addition, immune pathways

\footnotetext{
* Correspondence: boskabadymh@mums.ac.ir

${ }^{4}$ Neurogenic Inflammation Research Center, Mashhad University of Medical Sciences, Mashhad, Iran

${ }^{5}$ Department of Physiology, Faculty of Medicine, Mashhad University of Medical Sciences, Mashhad, Iran

Full list of author information is available at the end of the article
}

driven by T-helper $2\left(\mathrm{Th}_{2}\right)$ cells which produce IL-4, IL5 , and IL-13 are contributing in the pathophysiology of this disease. The imbalance of $\mathrm{Th}_{1} / \mathrm{Th}_{2}$ imbalance toward increased $\mathrm{Th}_{2}$ activity was indicated in the pathogenesis of asthma and allergies [3, 4]. Cytokines released from $\mathrm{Th}_{2}$ cells like IL- 4 and IL- 5 also stimulate IgE production by $\mathrm{B}$ cells which plays a role in allergic asthma [5]. Secretory phospholipases $\mathrm{A}_{2}\left(\mathrm{sPLA}_{2}\right)$ also may induce airway inflammation in asthma by release of arachidonic acid, generation of lysophospholipids, release of cytokines and the effect on inflammatory and

(c) The Author(s). 2019 Open Access This article is distributed under the terms of the Creative Commons Attribution 4.0 International License (http://creativecommons.org/licenses/by/4.0/), which permits unrestricted use, distribution, and reproduction in any medium, provided you give appropriate credit to the original author(s) and the source, provide a link to the Creative Commons license, and indicate if changes were made. The Creative Commons Public Domain Dedication waiver (http://creativecommons.org/publicdomain/zero/1.0/) applies to the data made available in this article, unless otherwise stated. 
immunological cells. In occupational asthma, increased serum total protein level was reported [6-8]. Airway remodeling which refers to the structural changes in the airways is another feature of asthma. Airway remodeling is believed to contribute to irreversible airflow obstruction and airway hyper responsiveness [9].

Currently used asthma medications reduce airway inflammation and diminish bronchospasm, but when treatment is discontinued, symptoms re-appear again [10]. Asthma has long been treated using medicinal plants in the Middle East, China and Europe [11]. Due to the derivation of many pharmaceutical drugs from plants origin, medicinal plants are seems to be the base of modern medicine [12]. Among the known medicinal herbs, the plants of genus Ocimum species, from Lamiaceae family, showed various therapeutic potentials. The leaves of these plants are used to relieve toothaches, sore throats, coughs, colds, bronchitis, laryngitis, nasal congestion and inflammation of the mouth and throat $[13,14]$. Between 50 and 150 species of herbs and shrubs were found for Ocimum genus in the tropical regions of Central and South America, Africa and Asia [15]. Ocimum basilicum (O. basilicum) is one of the main species of genus Ocimum [16]. O. basilicum or sweet basil is an annual species, original from Asia, cultivated in all the Mediterranean and tropical countries. Traditionally $O$. basilicum has been used to treat coughs, headaches, diarrhea, constipation, warts, worms, and kidney malfunctions [15]. Iranian O. basilicum are used to treat throat congestions, fevers and stomachache [15]. It was shown that $O$. basilicum crude methanolic extract down regulated TNF- $\alpha$, IL- $1 \beta$ and IL-2, and suppressed the induction of inducible nitric oxide synthase (iNOS) and the subsequent production of nitric oxide (NO) in LPS-stimulated RAW 264.7 macrophages in a time-dependent manner [17, 18]. Fixed oil of $O$. basilicum also blocked both cyclooxygenase and lipoxygenase pathways of arachidonic acid metabolism $[17,18]$. The aqueous extract of $O$. basilicum and several other medicinal plants inhibited giant cell formation in co-culture of Molt-4 cells with and without HIV-1 infection and showed inhibitory activity against HIV-1 reverse transcriptase [19]. Other pharmacological effects of this plant such as anti-aging, anti-cancer [20] and immune modulatory [21] have been previously reported. Therefore, the antiinflammatory and immune modulatory effects of this plant may result in improved asthma. In addition, the safety of the plant in animal and human models has been confirmed [22].

With regard to the different traditional and pharmacological effects of the plant, the effect of $O$. basilicum leaves extract on immunological and inflammatory factors in bronchoalveolar lavage fluid (BALF) and lung pathological changes in ovalbumin sensitized animals was evaluated in this study.

\section{Methods \\ Preparation of the plant extract}

The plant (O. basilicum) were collected from Mashhad area, (Razavi Khorasan province, Iran) and was identified by Mr. Joharchi in Research Center for Plant Sciences (specimen No. 12937061), the herbarium of School of Agriculture, Ferdowsi University of Mashhad as described previously [23].

To prepare macerated hydro-ethanolic extract, $100 \mathrm{~g}$ dried and grinded leaves of $O$. basilicum was dissolved in $1000 \mathrm{~mL}$ ethanol $70 \%$ in laboratory condition for $72 \mathrm{~h}$. Using rotary evaporator, the solvent was removed and the yield of obtain dry extract was $19 \%$.

\section{Animals and experimental groups}

Forty eight male Wistar rats (weighing $200 \pm 20$ g, randomly divided) were purchased from Animal house, Faculty of Medicine, Mashhad University of Medical Sciences, Mashhad, Iran, and were maintained in a stainless steel cage with clean filtered air (Maximiser, Thorens Caging System Inc., Hazleton, PA, U.S.A.) with free water and food ad libitum, temperature of $22 \pm 2{ }^{\circ} \mathrm{C}$ on a $12 \mathrm{~h} \mathrm{light/dark} \mathrm{cycle} \mathrm{during}$ experimental period [24]. The ethics committee of Mashhad University of Medical Sciences approved the Animal Experiments of the study (allowance number: 930842). The studies groups were described in Table 1 . The study was cried out according the regulations of the Institute of Laboratory Animals Resources Commission on Life Sciences [27].

\section{Animal sensitization}

Rats were sensitized as previously described [24] and Fig. 1. Briefly $1 \mathrm{mg} / \mathrm{kg}$ ovalbumin (OA), $(\geq 98 \%$, CAS Number: 9006-59-1, Sigma Chemical Ltd., UK) plus 100 mg $\mathrm{Al}(\mathrm{OH})_{3}$ (CAS Number: 21645-51-2, Sigma Chemical Ltd., UK) was administered intraperitoneal (i.p.) and rats were exposed to $2 \%$ OA aerosol with air flow of 8 lit/min for $20 \mathrm{~min} /$ day in a $0.8 \mathrm{~m}^{3}$ chamber, with animal normal-breathing. Saline was used instead of the ovalbumin solution in the control rats [24].

\section{Immunologic and inflammatory markers measurement}

One day after the end of sensitization, animals were sacrificed by i.p. administration of $50 \mathrm{mg} / \mathrm{kg}$ ketamine (CAS Number: 1867-66-9, Sigma Chemical Ltd., UK) and $5 \mathrm{mg} / \mathrm{kg}$ xylazine (CAS Number: 23076-35-9, Sigma Chemical Ltd., UK). The left lung was washed with one $\mathrm{mL}$ saline five times ( $5 \mathrm{~mL}$ totally). BALF was centrifuged at $2500 \mathrm{~g}$ at $4{ }^{\circ} \mathrm{C}$ for $10 \mathrm{~min}$ and supernatant was stored at $-70{ }^{\circ} \mathrm{C}$ [28] until analysis.

Cytokine and inflammatory levels including interleukin 4 (IL-4, Cat Number: ab100770, Abcam Company, 
Table 1 Studied groups (randomly divided)

\begin{tabular}{|c|c|c|c|c|}
\hline Groups & Name & Concentration & Dose & Reference \\
\hline Control & Non-sensitized rats $(C)$ & & & \\
\hline \multirow[t]{3}{*}{ Sensitized } & Non-treated, OA sensitized rats (S) & & & \\
\hline & $\begin{array}{l}\text { O. basilicum extract treatment } \\
\mathrm{S}+\text { OB } 0.75 \mathrm{mg} / \mathrm{ml} \\
\mathrm{S}+\mathrm{OB} 1.50 \mathrm{mg} / \mathrm{ml} \\
\mathrm{S}+\mathrm{OB} 3.00 \mathrm{mg} / \mathrm{ml}\end{array}$ & $0.75 \mathrm{mg} / \mathrm{ml} 1.50 \mathrm{mg} / \mathrm{ml} 3.00 \mathrm{mg} / \mathrm{ml}$ & $\begin{array}{l}150 \mathrm{mg} / \mathrm{kg} / \text { day } \\
300 \mathrm{mg} / \mathrm{kg} / \text { day } \\
600 \mathrm{mg} / \mathrm{kg} / \text { day }\end{array}$ & {$[23,25,26]$} \\
\hline & Dexamethasone treatment & $1.25 \mu \mathrm{g} / \mathrm{ml}$ & $250 \mathrm{mg} / \mathrm{kg} / \mathrm{day}$ & [24] \\
\hline
\end{tabular}

Addition of drugs did not change the water volume consumed by animals, which averaged $40 \mathrm{ml} /$ day/rat. Accordingly, daily dose of extract and dexamethasone are as shown in the Table. ( $n=8$ in each group). The doses of $O$. basilicum and dexamethasone were chosen according the previous studies as indicated in the Table

Cambridge, MA, USA), interferon gamma (IFN- $\gamma$, Cat Number: ab46107, Abcam Company, Cambridge, MA, USA), immunoglobulin E (IgE, Cat Number: ab157736, Abcam Company, Cambridge, MA, USA), phospholipase A2 (PLA2, Cat Number: MBS262388, MyBioSource Inc., San Diego, California, USA) and total protein (TP, Cat Number: 128500, Pars Azmoon. Co., Iran) in the BALF were measured by enzyme-linked immunosorbent assay (ELISA) sandwich method with appropriate protocol recommended by company. The ratio of IFN- $\gamma / \mathrm{IL} 4$ as an index of $\mathrm{Th}_{1} / \mathrm{Th}_{2}$ was also calculated.

\section{Pathological evaluation}

Histological examination was performed on right lung which was not lavaged. The right lung was fixed in $10 \%$ buffered formalin (37\%, CAS Number: M103999.2500Merck, Germany). The preserved tissues were dehydrated, embedded in paraffin, sectioned at $3 \mu \mathrm{m}$ thickness, and stained by hematoxylin-eosin (H\&E) solution. Cut number per sample was 3 to 4 cut. The slides were examined under a light microscope (Model Nikon E200) by a blinded pathologist to the experimental groups for quantifying the extent of lung histopathological changes. The number of microscopic fields was $8-10$ per section [28]. The pathological changes including interstitial inflammation, interstitial fibrosis, bleeding, plaque and emphysema were scored as 0 : if there were not pathological changes, 1 : if there was patchy changes and 2; when severe changes were present (in the most parts of the lung).

\section{Data analysis}

Means \pm SEM of the results were presented. Comparison between the results of control, sensitized and treated groups was done using one-way analysis of variance (ANOVA) with Tukey-Kramer's post-test. For statistical analysis, InStat (GraphPad Software, Inc., La Jolla, USA) package was used. Statistical significance was considered if $P$ values were less than 0.05 .

\section{Results}

The effect of the 0 . basilicum extract on BALF levels of IFN- $\gamma$, IL-4 and IgE

BALF level of IFN- $\gamma$ in $S$ group was not significantly different compared to $C$ group. There were significant decrease in BALF level of IFN- $\gamma$ in $\mathrm{S}+\mathrm{D}, \mathrm{S}+\mathrm{OB} 0.75, \mathrm{~S}+$ OB 1.50 and $\mathrm{S}+\mathrm{OB} 3.00$ groups compared to $\mathrm{C}$ group (all, $P<0.001$ ). Treatment of sensitized rats with two low concentrations of the extract and dexamethasone led to significant decrease in IFN- $\gamma$ as compared to $\mathrm{S}$ group $(P<0.001$ for all). A significant difference in BALF level

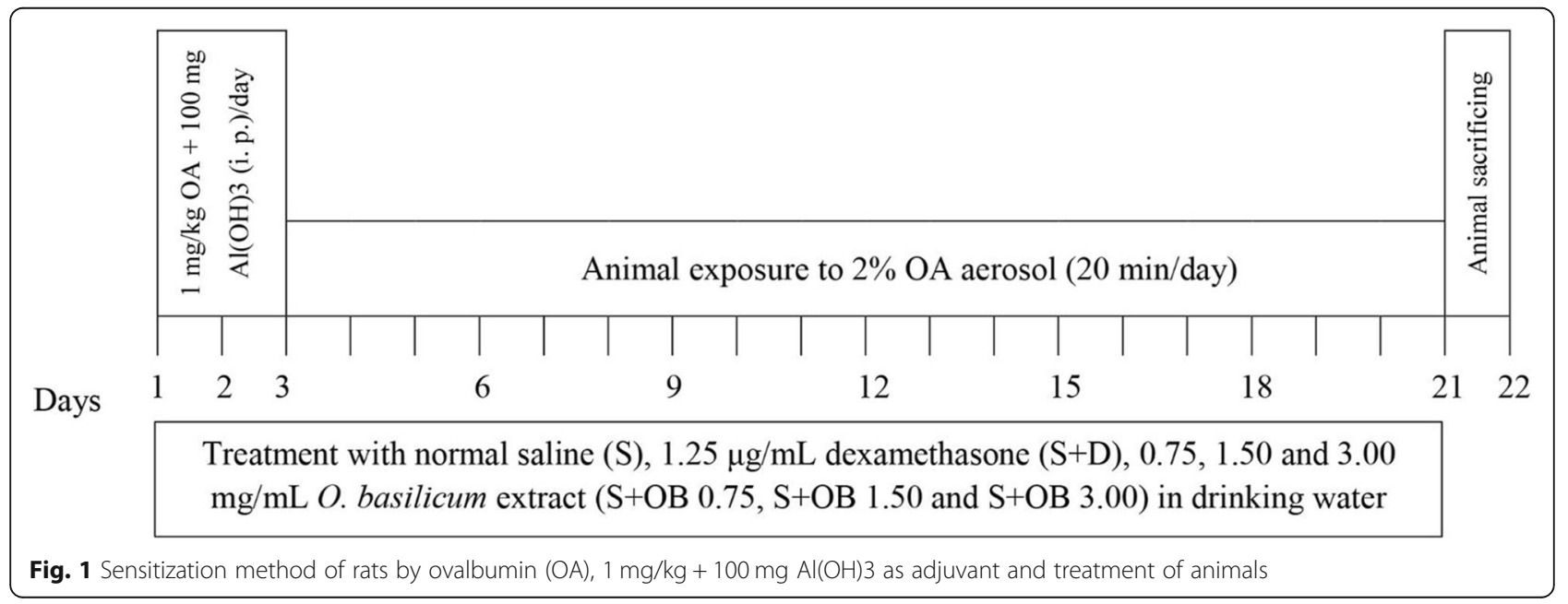


of IFN- $\gamma$ between $\mathrm{S}+\mathrm{OB} 3.00$ and $\mathrm{S}+\mathrm{D}$ groups was also seen $(P<0.001)$, (Fig. 2a).

BALF level of IL-4 in S group was significantly higher than $\mathrm{C}$ group $(P<0.001)$. BALF level of $\mathrm{IL}-4$ in $\mathrm{S}+\mathrm{D}$, $\mathrm{S}+\mathrm{OB} 0.75, \mathrm{~S}+\mathrm{OB} 1.50$ and $\mathrm{S}+\mathrm{OB} 3.00$ groups were significantly lower than $S$ group (all, $P<0.001$ ). There reduction of IL-4 level in S + OB $0.75, \mathrm{~S}+\mathrm{OB} 1.50$ and $\mathrm{S}+\mathrm{OB} 3.00$ groups were significantly more than $\mathrm{S}+\mathrm{D}$ group (all, $P<0.001$ ), (Fig. 2b).

The ratio of IFN- $\gamma / \mathrm{IL}-4$ was decreased in all untreated and treated sensitized groups compare to $\mathrm{C}$ group (all, $P<0.001)$. However, the ratio of IFN- $\gamma / \mathrm{IL}-4$ in sensitized rats treated with 1.5 and $3.0 \mathrm{mg} / \mathrm{mL}$ of the extract was significantly increase compared to $S$ group $(P<0.01$ and $P<$ 0.001 , respectively). The ratio of IFN- $\gamma / \mathrm{IL}-4$ in $\mathrm{S}+\mathrm{OB}$ 1.50 and $\mathrm{S}+\mathrm{OB} 3.00$ groups was also significantly higher compared to $\mathrm{S}+\mathrm{D}$ group $(P<0.001$ for both), (Fig. 3$)$.

BALF IgE levels were significantly higher in $\mathrm{S}, \mathrm{S}+\mathrm{D}$, S + OB 0.75 (all, $P<0.001)$, and S + OB $1.50(P<0.01)$ groups compared to that of $\mathrm{C}$ group. The BALF IgE levels in S + D, S + OB 0.75, S + OB 1.50 and S + OB 3.00 groups were significantly decreased compared to $S$ group $(P<0.01$ to $P<0.001)$. BALF IgE level in treated group with high concentration of the extract was also lower than $\mathrm{S}+\mathrm{D}$ group $(P<0.001)$, (Fig. 4$)$.

The effects of 1.5 and $3.0 \mathrm{mg} / \mathrm{mL}$ concentrations of the extract on all immunological mediator levels were significantly higher than the effect of its low $(0.75 \mathrm{mg} /$ $\mathrm{mL})$ concentration $(P<0.05$ to $P<0.001)$. The effect of $3.0 \mathrm{mg} / \mathrm{mL}$ of the extract on all immunological mediator levels was also significantly higher than the effect of 1.5 $\mathrm{mg} / \mathrm{mL}$ of the extract $(P<0.05$ to $P<0.001$, Table 2$)$.

\section{The effect of the 0 . basilicum extract on BALF levels of PLA2 and TP}

BALF level of $\mathrm{PLA}_{2}$ in $\mathrm{S}$ group were significantly higher than $C$ group (both, $P<0.001$ ). The level of PLA2 was decreased in all treated groups (all, $P<0.001$ ). PLA2

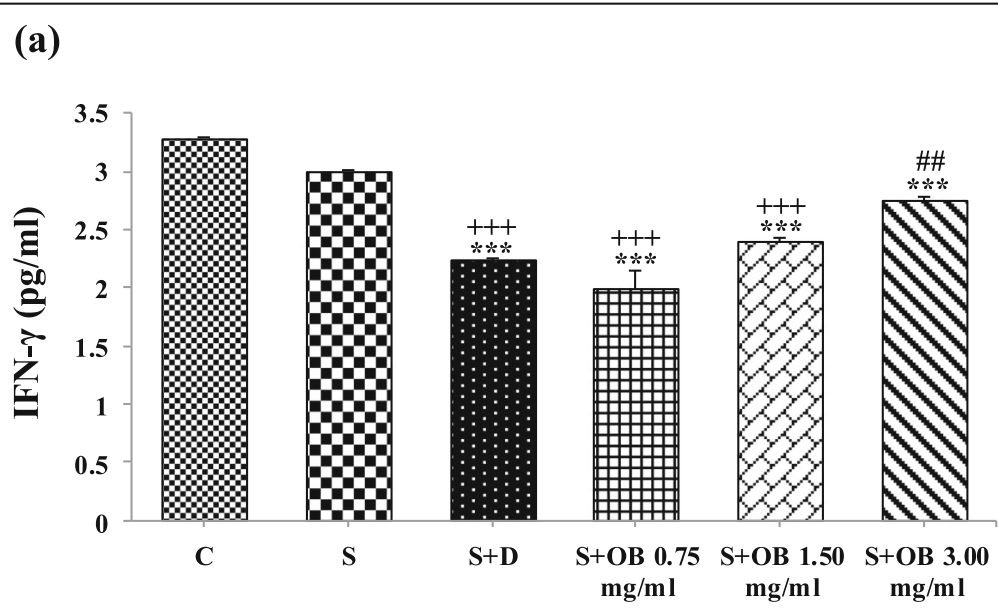

(b)

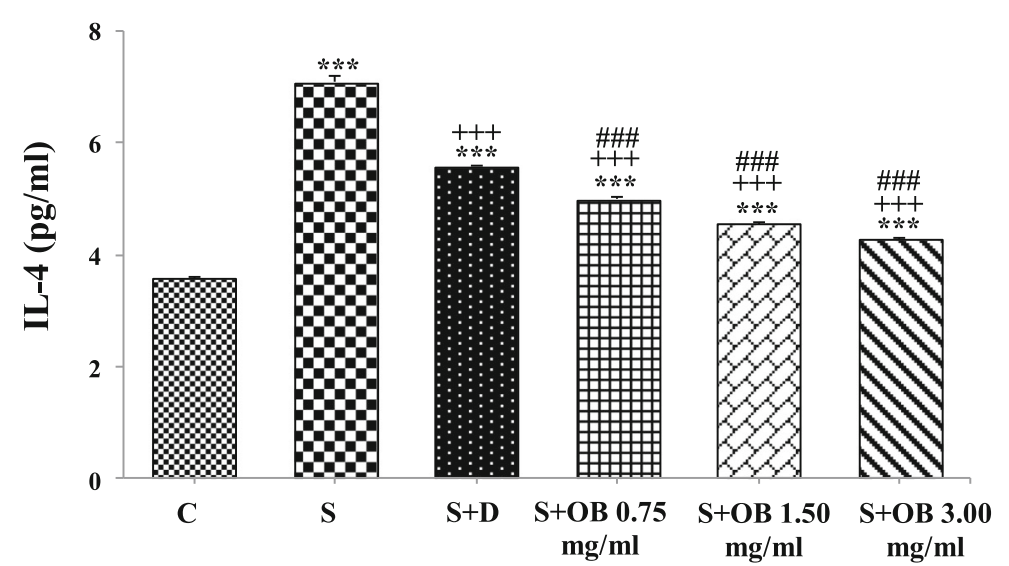

Fig. 2 Bronchoalveolar lavage fluid levels of IFN-ץ (a) and IL-4 (b), (mean \pm SEM) in the control (C), sensitized (S), treated sensitized animals with dexamethasone $(S+D)$ and three $O$. basilicum concentrations $(S+O B)$ groups, (in each group, $n=8)$. ${ }^{* * *} P<0.001$, comparison with $C$ group. +++ : $P<0.001$, comparison with $\mathrm{S}$ group. \#\#: $P<0.01$, \#\#\#: $p<0.001$, comparison with $S+D$ group. One-way analysis of variance (ANOVA) with Tukey-Kramer's post-test was used for statistical analysis 


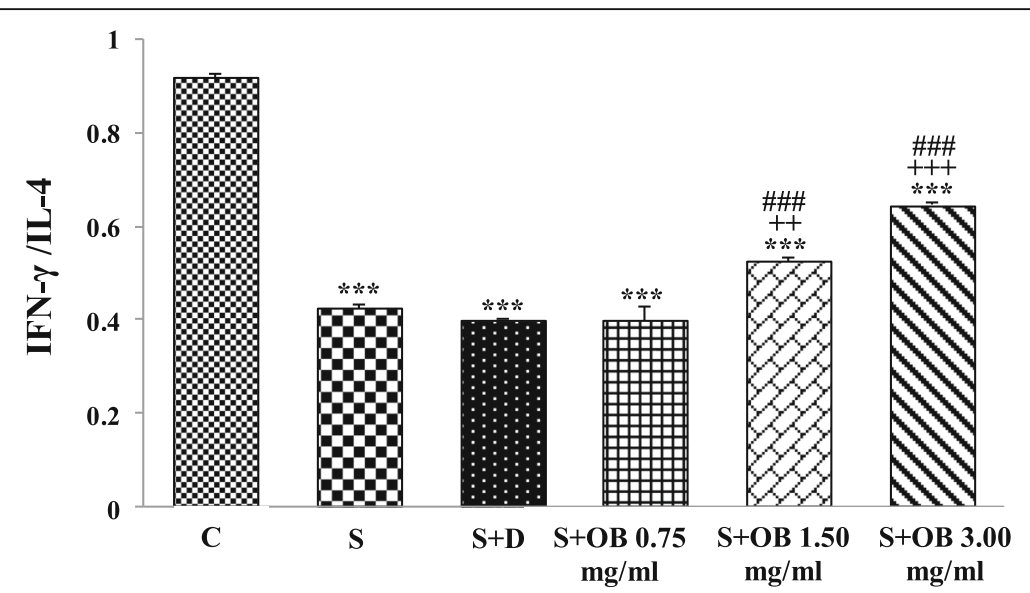

Fig. 3 Values (mean \pm SEM) of IFN- $\gamma$ to IL-4 ratio in the control (C), sensitized (S), treated sensitized animals with dexamethasone (S + D) and three 0 . basilicum concentrations $(S+O B$ ) groups, (in each group, $n=8$ ). ***: $P<0.001$, comparison with $C$ group. ++ : $P<0.01$, $+++P<0.001$, with $S$ group. \#\#\#: $P<0.001$, comparison with $S+D$ group. One-way analysis of variance (ANOVA) with Tukey-Kramer's post-test was used for statistical analysis

value in $\mathrm{S}+\mathrm{OB} 0.75$ was higher but in $\mathrm{S}+\mathrm{OB} 3.00$ groups showed significantly lower compared to $\mathrm{S}+\mathrm{D}$ group $(P<0.001$ and $P<0.05$, respectively), (Fig. 5a).

BALF level of TP in $\mathrm{S}$ group was significantly higher than $C$ group $(P<0.001)$. The level of TP was decreased in $\mathrm{S}+\mathrm{D}, \mathrm{S}+\mathrm{OB} 1.50$ and $\mathrm{S}+\mathrm{OB} 3.00$ groups compare to $\mathrm{S}$ group (all, $P<0.001$ ). The mean value of TP in $\mathrm{S}+\mathrm{OB}$ 3.00 group was significantly lower compared to $\mathrm{S}+\mathrm{D}$ group $(P<0.001)$. There was also no significant difference between $\mathrm{S}+\mathrm{OB} 3.00$ and $\mathrm{C}$ groups, (Fig. $5 \mathrm{~b}$ ).

The effects of 1.5 and $3.0 \mathrm{mg} / \mathrm{mL}$ of the extract on $\mathrm{PLA}_{2}$ and TP levels were significantly higher than the effect of its low $(0.75 \mathrm{mg} / \mathrm{mL})$ concentration $(P<$ 0.01 to $P<0.001)$. The high extract concentration effect on $\mathrm{PLA}_{2}$ and TP levels was significantly higher than the medium concentration effect $(P<0.05$ to $P<0.001$, Table 3).
The effect of the $O$. basilicum extract on lung pathological changes

All pathological scores in the $S$ group, were significantly higher than $C$ group $(P<0.05$ to $P<0.001$, Figs. 6,7 and 8$)$.

High extract concentration treatment caused significant improvement in interstitial inflammation, interstitial fibrosis and plaque but extract concentrations treatment caused significant improvement in bleeding and treatment with dexamethasone and two higher extract concentrations caused significant improvement in emphysema of sensitized rats $(P<0.05$ to $P<0.01$, Fig. 8$)$. There was no significant difference in pathological changes between $\mathrm{C}$ group and treated groups with dexamethasone and all concentrations of the extract (Fig. 7).

The effects of treatment with three concentrations of the extract on all pathological changes have no significant difference with each other (Table 4). No significant

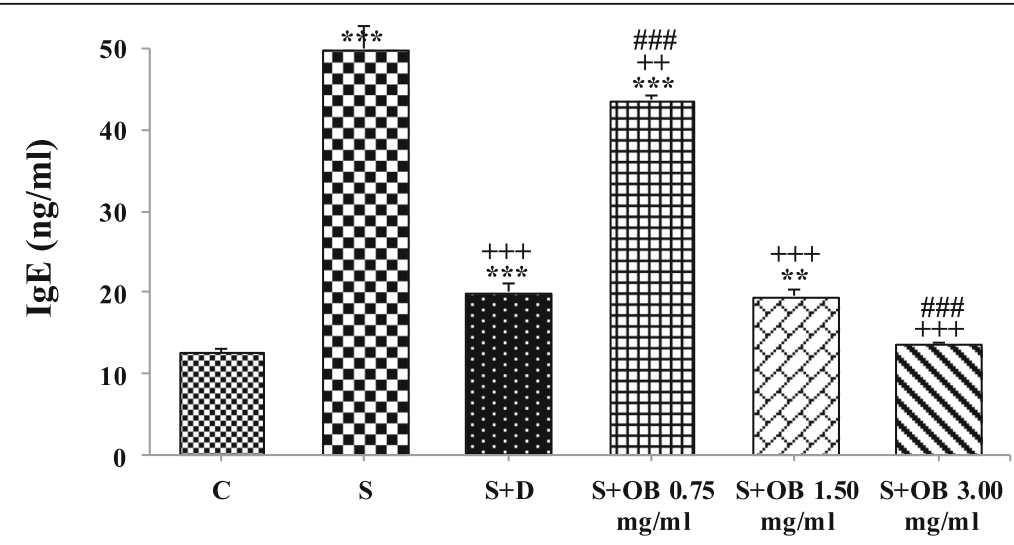

Fig. 4 Bronchoalveolar lavage fluid level of IgE (mean \pm SEM) in the control $(C)$, sensitized $(S)$, treated sensitized animals with dexamethasone $(S+D)$ and three $O$. basilicum concentrations $(S+O B)$ groups, (in each group, $n=8)$. **: $P<0.01$, ***: $P<0.001$, comparison with $C$ group. ++ : $P<$ $0.01,+++: P<0.001$, comparison with $S$ group. \#\#\#: $P<0.001$, comparison with $S+D$ group. One-way analysis of variance (ANOVA) with TukeyKramer's post-test was used for statistical analysis 
Table 2 IFN- $\gamma$, IL-4, IFN- $\gamma / \mathrm{IL}-4$ and IgE values in sensitized group treated with three different concentrations of O. basilicum (S + OB)

\begin{tabular}{|c|c|c|c|c|}
\hline Groups & IFN- $\gamma(\mathrm{pg} / \mathrm{ml})$ & IL-4 (pg/ml) & IFN- $\gamma / \mid \mathrm{L}-4$ & $\lg E(n g / m l)$ \\
\hline $\mathrm{S}+\mathrm{OB} 0.75 \mathrm{mg} / \mathrm{ml}$ & $1.99 \pm 0.15$ & $4.99 \pm 0.04$ & $0.40 \pm 0.03$ & $43.66 \pm 0.56$ \\
\hline $\mathrm{S}+\mathrm{OB} 1.50 \mathrm{mg} / \mathrm{ml}$ & $2.39 \pm 0.03^{+}$ & $4.55 \pm 0.03^{+++}$ & $0.53 \pm 0.01^{++}$ & $19.49 \pm 0.74^{+++}$ \\
\hline $\mathrm{S}+\mathrm{OB} 3.00 \mathrm{mg} / \mathrm{ml}$ & $2.75 \pm 0.03^{+++\#}$ & $4.27 \pm 0.04^{+++\# \#}$ & $0.64 \pm 0.01^{+++\# \#}$ & $13.70 \pm 0.11^{+++\# \# \#}$ \\
\hline
\end{tabular}

${ }^{+}: p<0.05,{ }^{++}: p<0.01,{ }^{+++}: p<0.001$, comparison with $\mathrm{S}+\mathrm{OB} 0.75$ group. ${ }^{\#}: p<0.05,{ }^{\# \#}: p<0.01,{ }^{\# \# \#}: p<0.001$, comparison between $\mathrm{S}+\mathrm{OB} 3.00$ and $\mathrm{S}+\mathrm{OB} 1.50$ groups. Values are expressed as mean \pm SEM. One-way analysis of variance (ANOVA) with Tukey-Kramer's post-test was used for statistical comparisons, (in each group, $n=8$ )

difference was observed between dexamethasone treatment and all extract concentrations treatment on pathological changes (Figs. 7 and 8).

\section{Discussion}

Significant increases in IL-4, IgE, PLA 2 and TP levels, significant decrease in IFN- $\gamma / \mathrm{IL}-4$ ratio, increased all pathological changes were seen in a rat model of asthma compared to control group. These changes indicated the induction of a rat model of asthma which supported by previous studies [29-31]. There are three phases in allergic asthma development including 1) Induction phase in which $\mathrm{T}$ helper cytokines play a role in the development of asthma, 2) Early-phase asthmatic reaction (EAR) in which preformed mediators, newly synthesized lipid mediators and cytokines are the main mediators, and 3) Late-phase asthmatic reaction (LAR) in which neutrophils, eosinophils, $\mathrm{T}$ cells, macrophages, dendritic cells, and structural cells produce inflammatory molecules and lead to inflammation and structural changes in airway

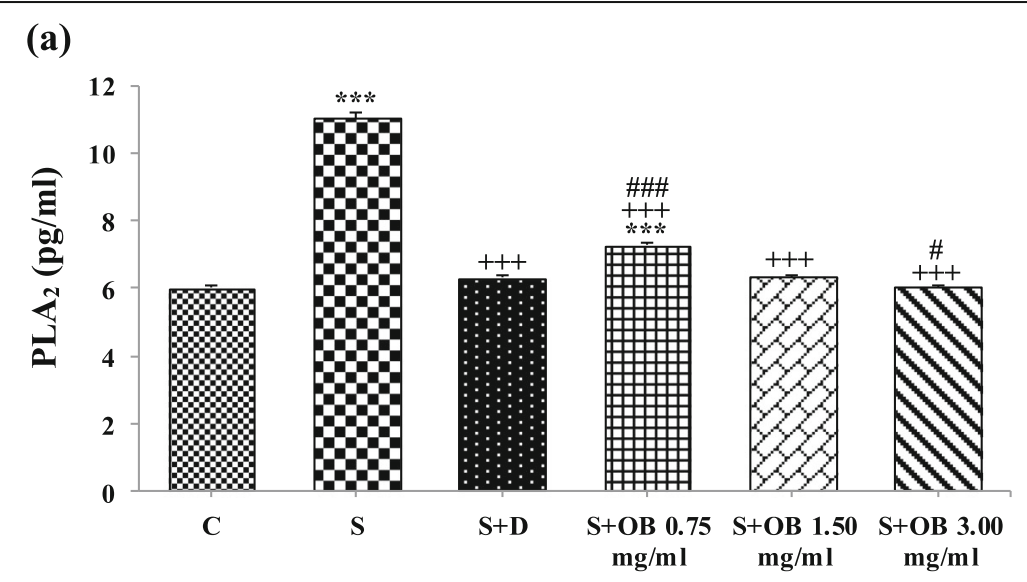

(b)

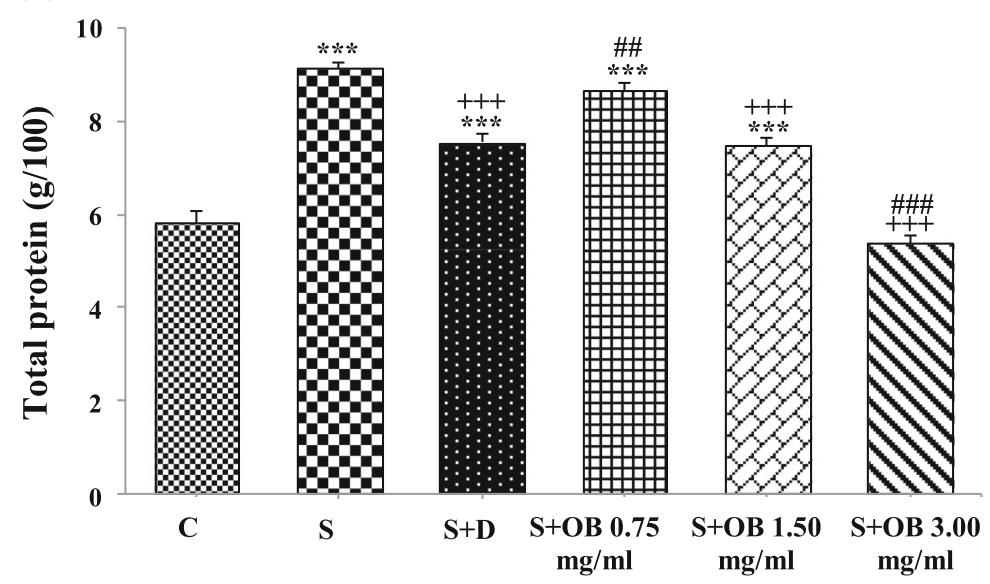

Fig. 5 Bronchoalveolar lavage fluid levels of PLA $(\mathbf{a})$ and total protein (b), (mean $\pm S E M)$ in the control (C), sensitized (S), treated sensitized animals with dexamethasone $(S+D)$ and three $O$. basilicum concentrations $(S+O B)$ groups, (in each group, $n=8)$. ${ }^{* *}: P<0.001$, comparison with $C$ group. +++ : $P<0.001$, comparison with $S$ group. \#: $P<0.05$, \#\#: $P<0.01$, \#\#\#: $P<0.001$, comparison with $S+D$ group. One-way analysis of variance (ANOVA) with Tukey-Kramer's post-test was used for statistical analysis 
Table $3 \mathrm{PLA}_{2}$ and total protein (TP) values in sensitized group treated with three different concentrations of O. basilicum (S+ $\mathrm{OB})$

\begin{tabular}{|c|c|c|}
\hline Groups & $\mathrm{PLA} \mathrm{A}_{2}(\mathrm{pg} / \mathrm{ml})$ & TP $(g / 100)$ \\
\hline $\mathrm{S}+\mathrm{OB} 0.75 \mathrm{mg} / \mathrm{ml}$ & $7.28 \pm 0.078$ & $8.67 \pm 0.18$ \\
\hline $\mathrm{S}+\mathrm{OB} 1.50 \mathrm{mg} / \mathrm{ml}$ & $6.35 \pm 0.04^{+++}$ & $7.48 \pm 0.17^{++}$ \\
\hline $\mathrm{S}+\mathrm{OB} 3.00 \mathrm{mg} / \mathrm{ml}$ & $6.06 \pm 0.032^{+++\#}$ & 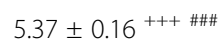 \\
\hline
\end{tabular}

well [32]. The results of the current study indicated the induction of all three phases of development of asthma.

Airway inflammation is the main characteristic feature of asthma, and recent strategies for managing asthma have been emphasized on suppression of Th2-mediated airway inflammation [3]. Therefore, preventive treatments should minimize the airway inflammation caused by asthma.

Most of the above-mentioned variables were improved by administration of $O$. basilicum and dexamethasone. Anti-inflammatory effect of dexamethasone on respiratory tract in asthmatic mice [33] and anti-inflammatory activity of $O$. basilicum against different mediatorinduced paw edema in rats through blocked of arachidonic acid metabolism, both cyclooxygenase and lipoxygenase pathways [18] has been shown, supporting the results of this study.

Various plant constituents including glycosidic structures, flavonoides and saponines showed anti-inflammatory activity [34]. In O. basilicum leaves, flavonoids such as quercetin, isoquercetrin, kaempferol and rutin, and glycosids like esculin and syringin have been found [35] that may be responsible for the anti-inflammatory activity. $O$ basilicum is one of the most important aromatic plants with aromatic compounds including 4-allylphenol, anethole, anisaldehyde, benzyl alcohol, cuminaldehyde, ethyl cinnamate, methyl benzoate, methyl cinnamate, methyl eugenol, methyl salicylate, phenethyl alcohol, phenyl acetaldehyde, safrole, benzaldehyde and estragole [35]. Anti-inflammatory effects of the $O$. basilicum essential oil and its main compound estragole [36], and volatile constituents extracted from the leaves of $O$. basilicum such as eucalyptol, linalool, borneol acetate, alpha-bergamoten, germacrene and a triterpenoid alphaamyrin were previously reported [37-39]. However, further studies are needed to demonstrate which one of these chemical compounds from $O$. basilicum are the most important chemicals for its anti-inflammatory effects.

An imbalance of Th1/Th2 cells can lead to tracheal hyper-responsiveness and inflammation. Asthmatic airway inflammation can be modulated by The Th1/ Th2 balance [3]. Immunomodulatory properties of aqueous extract of this plant and some of its constituents on human immune cells suggest the potent natural immunomodulatory of these influencing several types of immune-responses and may have potential health benefits [21]. O. basilicum extract improved histological, morphometric and immunohistochemical changes induced by cadmium in albino rats [40]. Immuno-stimulant effects of this plant against gibberellic acid and auxin supplementation in broilers ration [41] were also supported the results of the present study. Therefore, the plant extract may have therapeutic effect on inflammatory diseases via reduction of involved cells in the respiratory tract inflammation.

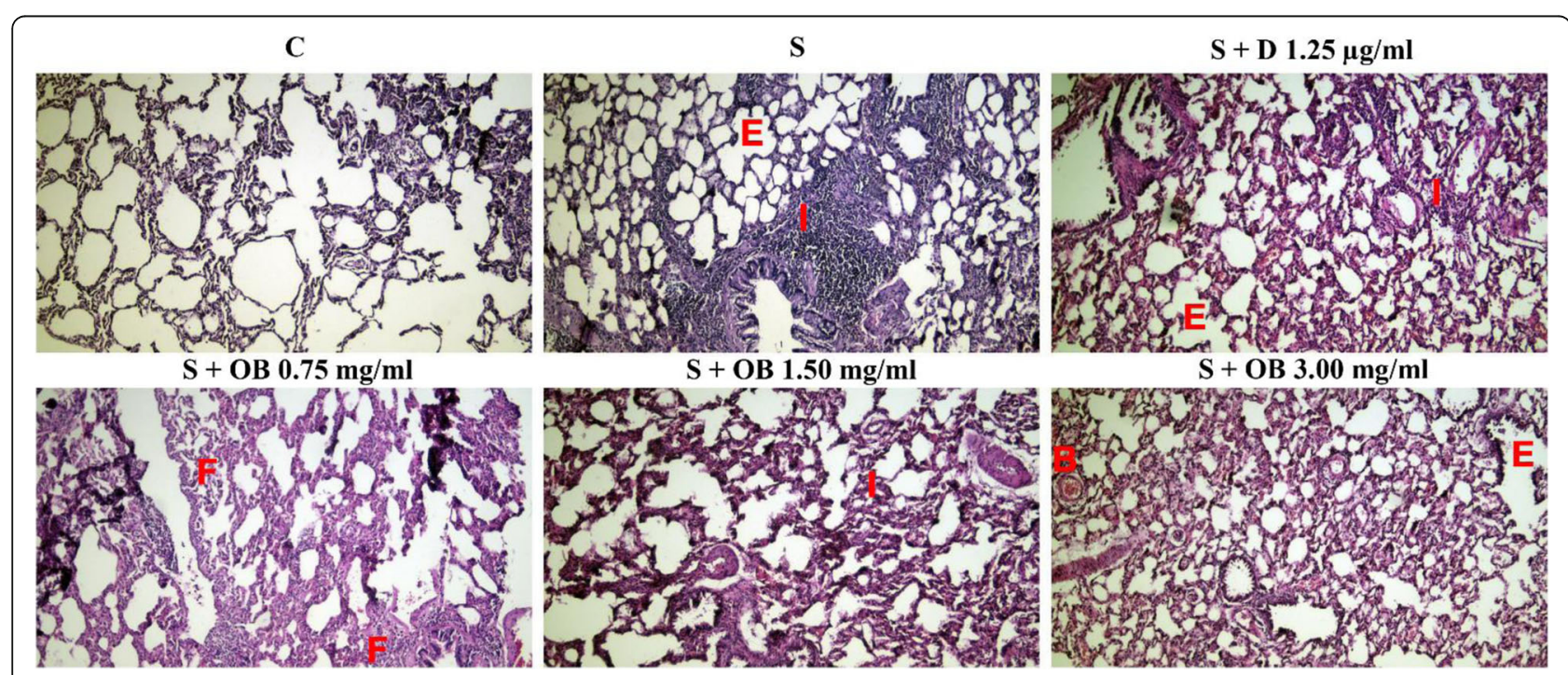

Fig. 6 Photograph of a lung specimen with interstitial inflammation (I), interstitial fibrosis (F), bleeding (B) and emphysema (E) in the control (C), sensitized $(S)$, treated sensitized animals with dexamethasone $(S+D)$ and three O. basilicum concentrations $(S+O B)$ groups, (magnification 100x) 


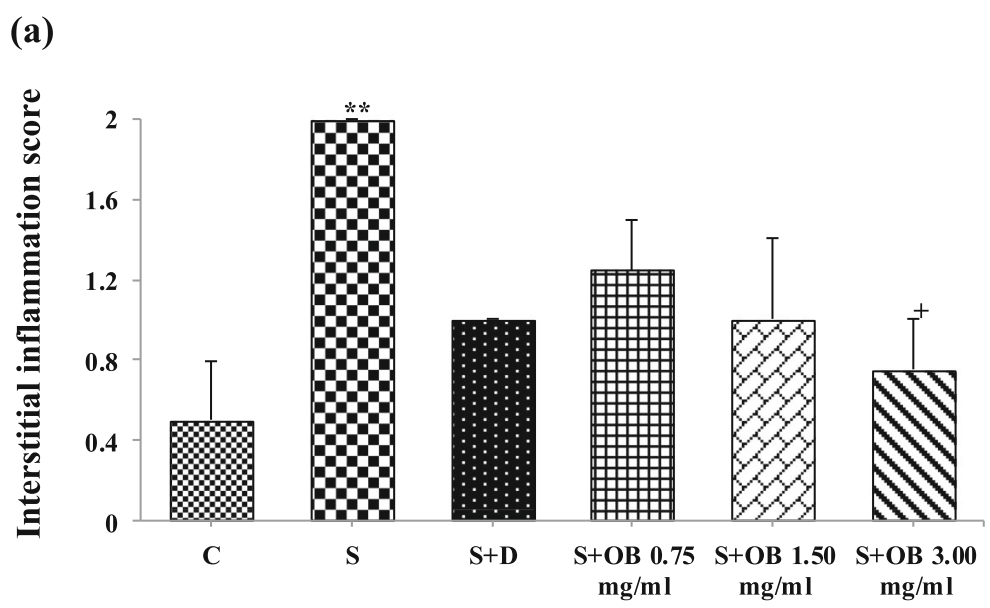

(b)

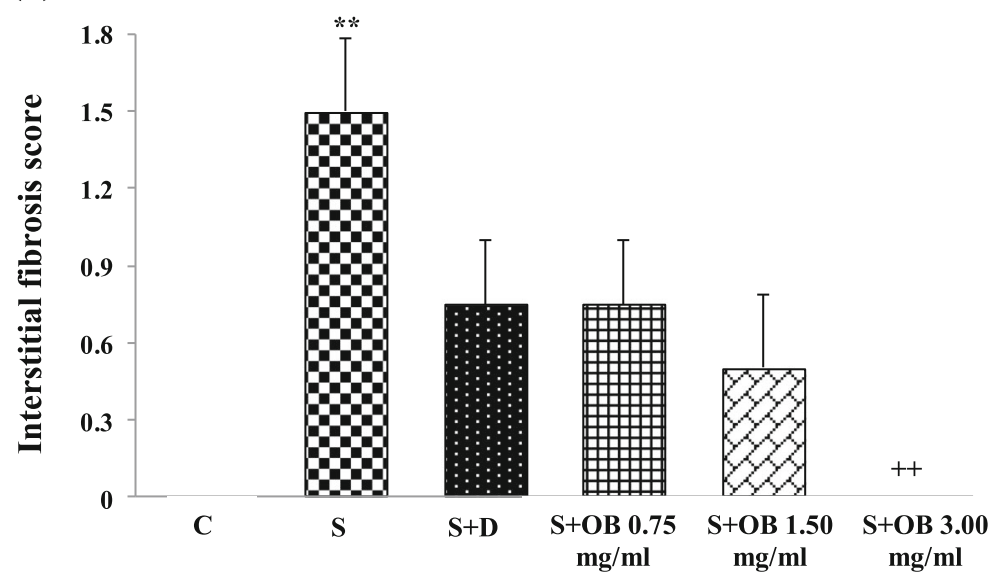

(c)

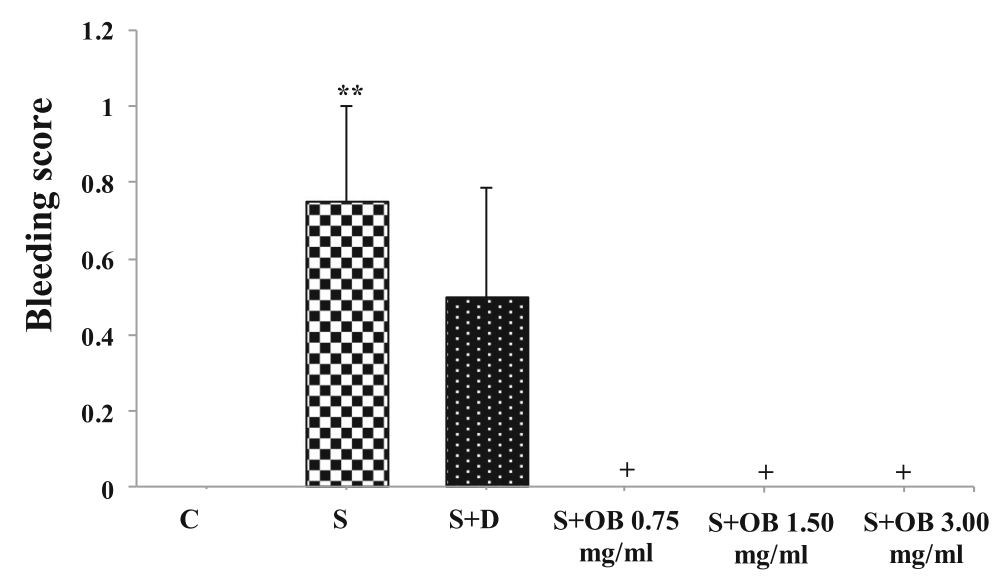

Fig. 7 The score of interstitial inflammation (a), interstitial fibrosis (b) and bleeding (c) in the control (C), sensitized (S), treated sensitized animals with dexamethasone $(S+D)$ and three $O$. basilicum concentrations $(S+O B)$ groups, (in each group, $n=8$ ). *: $P<0.05$, **: $P<0.01$, comparison with $C$ group. +: $P<0.05,++: P<0.01$, comparison with $S$ group. One-way analysis of variance (ANOVA) with Tukey-Kramer's post-test was used for statistical analysis

This study also demonstrated that the effects of the plant extract on various variables in sensitized rats were concentration dependent. In fact, the effects of two higher concentrations of the extract on all immunological and inflammatory mediators levels were significantly higher than the effect of its low concentration and 

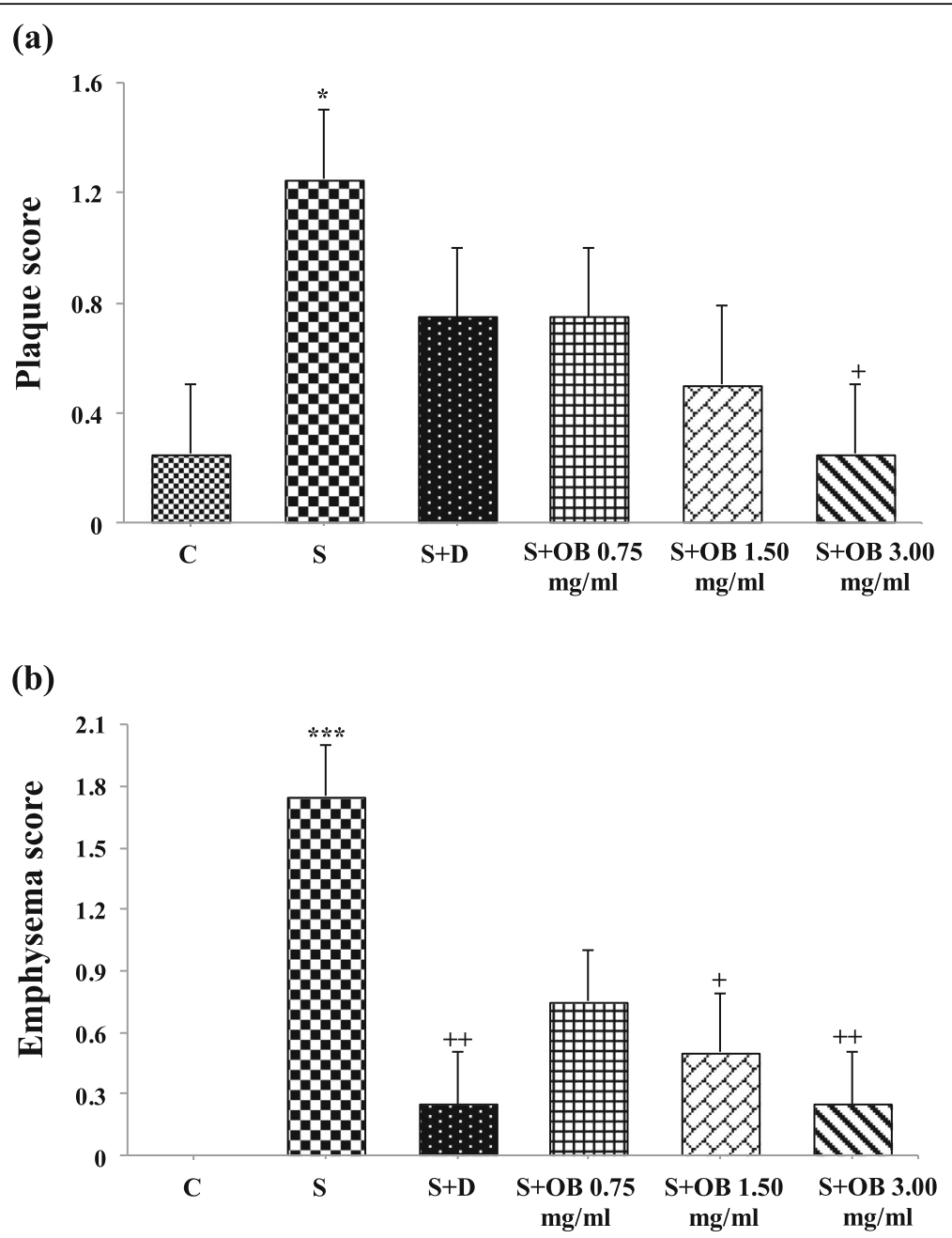

Fig. 8 The score of airway plaque (a) and emphysema (b) in the control (C), sensitized (S), treated sensitized animals with dexamethasone (S+D) and three $O$. basilicum concentrations $(S+O B)$ groups, (in each group, $n=8$ ). $*: p<0.05$, ***: $p<0.001$, comparison with $C$ group. $+: p<0.05,++$ : $p<0.01$, comparison with $\mathrm{S}$ group. One-way analysis of variance (ANOVA) with Tukey-Kramer's post-test was used for statistical analysis

the effect of high extract concentration was significantly higher than its medium concentration.

In treated group with high extract concentration, its effect on the levels of IFN- $\gamma$, IgE, PLA 2 and TP, in treated groups with all extract concentrations, their effects on IL-4 level and the in treated groups with two higher extract concentrations, their effects on the ratio of IFN- $\gamma$ to IL-4 were significantly higher than dexamethasone treatment. However, the effects of low extract concentration on IgE, $\mathrm{PLA}_{2}$ and TP levels were significantly lower than dexamethasone treatment. These results showed comparable or even more potent preventive effect of the extract compared to the dexamethasone effect. These findings also indicated more specific effect of the extract on IFN- $\gamma / \mathrm{IL}-4$ ratio and therefore on $\mathrm{Th}_{1} / \mathrm{Th}_{2}$ balance compared dexamethasone treatment in sensitized rats.

The effect of the extract on immunological changes including IFN- $\gamma$, IL-4, IgE, PLA2 and TP levels and the ratio of IFN- $\gamma /$ IL4 as an index of Th1/Th2 as well its

Table 4 Pathological changes in sensitized group treated with three different concentrations of O. basilicum (S + OB)

\begin{tabular}{llllll}
\hline Groups & Interstitial inflammation & Interstitial fibrosis & Bleeding & Plaque & Emphysema \\
\hline S + OB $0.75 \mathrm{mg} / \mathrm{ml}$ & $1.25 \pm 0.25$ & $0.75 \pm 0.25$ & $0 \pm 0$ & $0.75 \pm 0.25$ & $0.75 \pm 0.25$ \\
$\mathrm{~S}+\mathrm{OB} 1.50 \mathrm{mg} / \mathrm{ml}$ & $1 \pm 0.4$ & $0.5 \pm 0.29$ & $0 \pm 0$ & $0.5 \pm 0.29$ & $0.5 \pm 0.29$ \\
$\mathrm{~S}+\mathrm{OB} 3.00 \mathrm{mg} / \mathrm{ml}$ & $0.75 \pm 0.25$ & $0 \pm 0$ & $0 \pm 0$ & $0.25 \pm 0.25$ & $0.25 \pm 0.25$
\end{tabular}

Values are presented as mean \pm SEM. Pathological changes were not significantly different on among different extract concentrations. One-way analysis of variance (ANOVA) with Tukey-Kramer's post-test was used for statistical comparisons, (in each group, $n=8$ ) 
effect on pathological changes were shown in the current study. In previous studies, the effect of $O$. basilicum extract on depression like behavior, tracheal responsiveness, lung inflammatory cells and oxidantantioxidant biomarkers in the OA-sensitized rats was shown $[23,25,26]$ which support the findings of the present studies. However, this study has some limitations such as the assessment of qualitative and quantitative extract composition which should be examined in further studies.

\section{Conclusions}

Anti-inflammatory and immunomodulatory effects of $O$. basilicum extract on asthma were shown by increasing the IFN- $\gamma / \mathrm{IL}-4$ ratio $\left(\mathrm{Th}_{1} / \mathrm{Th}_{2}\right.$ balance) and decreasing BALF levels of IgE, PLA 2 and TP as well as improvement of pathological changes in sensitized rats by the plant. These findings suggest the preventive therapeutic potential for the $O$. basilicum extract on animal model of asthma.

\section{Abbreviations}

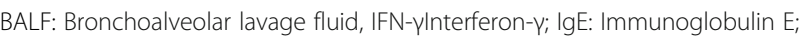
IL-4: Interleukin 4; LAR: Late-phase asthmatic reaction; OB: Ocimum basilicum; OA: Ovalbumin; PLA2: Phospholipase A2; TP: Total protein

\section{Acknowledgments}

Not applicable.

\section{Authors' contributions}

MHB designed the study, conceived and planned the experiments. AM was involved in planning and supervised the work. NE performed the experiments and wrote the manuscript in consultation with SS. NMR performed the histological examination of the lung. All authors read and approved the final manuscript.

\section{Funding}

This study was financially supported by a grant from Research Council of Mashhad University of Medical Sciences.

\section{Availability of data and materials}

All the data supporting contained within the manuscript. Detailed data could be also obtained from corresponding author.

\section{Ethics approval and consent to participate}

The study was approved by the ethics committee of Mashhad University of Medical Sciences for Animal Experiments, Mashhad University of Medical Sciences, Mashhad, Iran, (allowance number: 930842).

\section{Consent for publication}

Not applicable.

\section{Competing interests}

The authors declare that they have no competing interests.

\section{Author details}

'Department of Biology, Faculty of Science, Ferdowsi University of Mashhad, Mashhad, Iran. ${ }^{2}$ Department of Pathology, Faculty of Medicine, Mashhad University of Medical Sciences, Mashhad, Iran. ${ }^{3}$ Department of Physiology, School of Medicine, Zahedan University of Medical Sciences, Zahedan, Iran. ${ }^{4}$ Neurogenic Inflammation Research Center, Mashhad University of Medical Sciences, Mashhad, Iran. ${ }^{5}$ Department of Physiology, Faculty of Medicine, Mashhad University of Medical Sciences, Mashhad, Iran.
Received: 27 May 2019 Accepted: 21 November 2019

Published online: 04 December 2019

\section{References}

1. Murdoch JR, Lloyd CM. Chronic inflammation and asthma. Mutat Res Fundam Mol Mech Mutagen. 2010;690:24-39.

2. Dodig S, Richter D, Zrinski-Topić R. Inflammatory markers in childhood asthma. Clin Chem Lab Med. 2011;49:587-99.

3. Keyhanmanesh $R$, Saadat S, Mohammadi M, Shahbazfar AA, Fallahi M. The protective effect of a-Hederin, the active constituent of Nigella sativa, on lung inflammation and blood cytokines in ovalbumin sensitized Guinea pigs. Phytother Res. 2015;29:1761-7.

4. Saadat S, Mohammadi M, Fallahi M, Aslani MR. The protective effect of ahederin, the active constituent of Nigella sativa, on tracheal responsiveness and lung inflammation in ovalbumin-sensitized Guinea pigs. J Physiol Sci. 2015;65:285-92

5. Sandeep T, Roopakala MS, Silvia CRWD, Chandrashekara S, Rao M. Evaluation of serum immunoglobulin E levels in bronchial asthma. Lung India. 2010;27:138.

6. Bowton DL, Dmitrienko AA, Israel E, Zeiher BG, Sides GD. Impact of a soluble phospholipase A2 inhibitor on inhaled allergen challenge in subjects with asthma. J Asthma. 2005;42:65-71.

7. Pniewska E, Pawliczak R. The involvement of phospholipases A2 in asthma and chronic obstructive pulmonary disease. Mediat Inflamm. 2013;2013:1-12.

8. Qureshi S, Memon S, Laghari A, Ghanghro A. Metabolic total protein investigation in local industry workers exposed to acid anhydrides. Sind Univ Res J. 2015:41:63-6.

9. Shifren A, Witt C, Christie C, Castro M. Mechanisms of remodeling in asthmatic airways. J Allergy. 2012;2012:1-12.

10. Quirce S, Phillips-Angles E, Dominguez-Ortega J, Barranco P. Biologics in the treatment of severe asthma. Allergol Immunopathol. 2017:45:45-9.

11. Zhang HP, Wang L, Wang Z, Xu XR, Zhou XM, Liu G, et al. Chinese herbal medicine formula for acute asthma: A multi-center, randomized, double-blind, proof-of-concept trial. Resen Med. 2018;2018/07(140):42-9.

12. Parveen A, Akash MSH, Rehman K, Mahmood Q, Qadir Ml. Analgesic, antiinflammatory and anti-pyretic activities of Caesalpinia decapetala. Bioimpacts. 2014;4:43.

13. Vieira RF, Simon JE. Chemical Characterization of basil (Ocimum Spp.) found in the markets and used in traditional medicine in Brazil. Econ Bot. 2000; 2000/04(54):207-16.

14. Abirami SG, Nirmala P. A comparative-invitro study of anticancer effect of Mentha piperita, Ocimum basilicum and Coleus aromaticus against human laryngeal epidermoid carcinoma (HEP-2) cell lines. J Med Plants Stud. 2014; 2:6-9.

15. Javanmardi J, Khalighi A, Kashi A, Bais HP, Vivanco JM. Chemical Characterization of Basil (Ocimum basilicuml.) Found in Local Accessions and Used in Traditional Medicines in Iran. J Agric Food Chem. 2002;2002/10(50): 5878-83.

16. Prakash P, Gupta N. Therapeutic uses of Ocimum sanctum Linn (Tulsi) with a note on eugenol and its pharmacological actions: a short review. Indian J Physiol Pharmacol. 2005:49:125.

17. Selvakkumar C, Gayathri B, Vinaykumar KS, Lakshmi BS, Balakrishnan A Potential anti-inflammatory properties of crude alcoholic extract of Ocimum basilicum L. in human peripheral blood mononuclear cells. J Health Sci. 2007:53:500-5.

18. Singh S. Mechanism of action of antiinflammatory effect of fixed oil of Ocimum basilicum Linn. Indian J Exp Biol. 1999;37:248-52.

19. Yamasaki K, Nakano M, Kawahata T, MORI H, OTAKE T, UEDA N, et al. AntiHIV-1 activity of herbs in Labiatae. Biol Pharm Bull. 1998;21:829-33.

20. Katalinic $V$, Milos $M$, Kulisic $T$, Jukic $M$. Screening of 70 medicinal plant extracts for antioxidant capacity and total phenols. Food Chem. 2006; 94:550-7.

21. Tsai K, Lin B, Perng D, Wei J, Yu Y, Cherng J-M. Immunomodulatory effects of aqueous extract of Ocimum basilicum (Linn.) and some of its constituents on human immune cells. J Med Plant Res. 2011:5:1873-83.

22. Manosroi J, Dhumtanom P, Manosroi A. Anti-proliferative activity of essential oil extracted from Thai medicinal plants on KB and P388 cell lines. Cancer Lett. 2006;235:114-20.

23. Eftekhar N, Moghimi A, Boskabady MH. The effects of Ocimum basilicum extract and its constituent, rosmarinic acid on total and differential blood WBC, serum levels of NO, MDA, thiol, SOD, and CAT in ovalbumin sensitized rats. Iran J Pharm Res. 2018;17:1371. 
24. Kaveh M, Eidi A, Nemati A, Boskabady MH. The extract of Portulaca oleracea and its constituent, alpha Linolenic acid affects serum oxidant levels and inflammatory cells in sensitized rats. Iran J Allergy Asthma Immunol. 2017; 16:256-70.

25. Neamati A, Talebi S, Hosseini M, Boskabady MH, Beheshti F. Administration of Ethanolic Extract of Ocimum Basilicum leaves attenuates depression like behavior in the rats sensitized by ovalbumin. Curr Nutr Food Sci. 2016;12: 72-8.

26. Eftekhar N, Moghimi A, Boskabady MH, Kaveh M, Shakeri F. Ocimum basilicum affects tracheal responsiveness, lung inflammatory cells and oxidant-antioxidant biomarkers in sensitized rats. Drug Chem Toxicol. 2019; 42:286-94.

27. Clark JD, Gebhart GF, Gonder JC, Keeling ME, Kohn DF. The 1996 guide for the care and use of laboratory animals. ILAR J. 1997;38:41-8.

28. Saadat S, Beheshti F, Askari VR, Hosseini M, Mohamadian Roshan N, Boskabady MH. Aminoguanidine affects systemic and lung inflammation induced by lipopolysaccharide in rats. Respir Res. 2019;20:96-108.

29. Boskabady MH, Jalali S. Effect of carvacrol on tracheal responsiveness, inflammatory mediators, total and differential WBC count in blood of sensitized Guinea pigs. Exp Biol Med. 2013;238:200-8.

30. Gholamnezhad Z, Koushyar H, Byrami G, Boskabady MH. The extract of crocus sativus and its constituent safranal, affect serum levels of endothelin and total protein in sensitized Guinea pigs. Iran J Basic Med Sci. 2013;16:1022.

31. Andersson S, Zackrisson C, Behrens K, Hemsen A, Forsberg K, Linden M, et al. Effect of allergen provocation on inflammatory cell profile and endothelin-like immunoreactivity in Guinea-pig airways. Allergy. 1995;50:349-58.

32. Bloemen K, Verstraelen S, Van Den Heuvel R, Witters H, Nelissen I, Schoeters $\mathrm{G}$. The allergic cascade: review of the most important molecules in the asthmatic lung. Immunol Lett. 2007;113:6-18.

33. Tang $X$, Yu H, Deng $H$, Chen $X$, Fan $H$, Gong $Y$, et al. Pathogenic mechanism of CD8 (+) CD28 (-) T cell and the effect of dexamethasone in asthmatic mouse. Zhonghua Yi Xue Za Zhi. 2011;91:1861-5.

34. Benedec D, Pârvu AE, Oniga I, Toiu A, Ba T. Effects of Ocimum basilicum L extract on experimental acute inflammation. 3. 2007;111:1065-9.

35. Marwat SK, Khan MS, Ghulam S, Anwar N, Mustafa G, Usman K. Phytochemical constituents and pharmacological activities of sweet BasilOcimum basilicum L.(Lamiaceae). Asian J Chem. 2011:23:3773.

36. Rodrigues LB, Martins AOBPB, Cesário FRAS, FF EC, de Albuquerque TR, MNM F, et al. Anti-inflammatory and antiedematogenic activity of the Ocimum basilicum essential oil and its main compound estragole: in vivo mouse models. Chem Biol Interact. 2016;257:14-25.

37. Peana AT, D'Aquila PS, Panin F, Serra G, Pippia P, Moretti MDL. Antiinflammatory activity of linalool and linalyl acetate constituents of essential oils. Phytomedicine. 2002;9:721-6.

38. Juergens UR, Dethlefsen U, Steinkamp G, Gillissen A, Repges R, Vetter $H$. Anti-inflammatory activity of 1.8-cineol (eucalyptol) in bronchial asthma: a double-blind placebo-controlled trial. Respir Med. 2003;97:250-6.

39. Aragao GF, Pinheiro MCC, Bandeira PN, Lemos TLG, Viana GSdB. Analgesic and anti-inflammatory activities of the isomeric mixture of alpha-and betaamyrin from Protium heptaphyllum (Aubl.) march. J Herb Pharmacother 2008;7:31-47.

40. Sakr SA, Nooh HZ. Effect of Ocimum basilicum extract on cadmium-induced testicular histomorphometric and immunohistochemical alterations in albino rats. Anat Cell Biol. 2013;46:122-30.

41. Al-Sahhaf ZY. Effect of ocimum basilicum extract on sodium hypochlorite-induced biochemical alterations in rabbits. Paripex Indian J Res. 2018;7.

\section{Publisher's Note}

Springer Nature remains neutral with regard to jurisdictional claims in published maps and institutional affiliations.

\section{Ready to submit your research? Choose BMC and benefit from}

- fast, convenient online submission

- thorough peer review by experienced researchers in your field

- rapid publication on acceptance

- support for research data, including large and complex data types

- gold Open Access which fosters wider collaboration and increased citations

- maximum visibility for your research: over $100 \mathrm{M}$ website views per year

At $\mathrm{BMC}$, research is always in progress.

Learn more biomedcentral.com/submissions 